
\title{
25 Research Square \\ A DFT Study of the Impact of Doping on the Electronic and Optical Properties of Indium Nitride Nanocage
}

\section{Amarjyoti Das}

North Eastern Regional Institute of Science and Technology

Rajesh Kumar Yadav ( $\square$ rrpryadav@gmail.com )

North Eastern Regional Institute of Science and Technology https://orcid.org/0000-0001-6867-3541

\section{Research Article}

Keywords: Nanocage, electronic properties, optical properties, DFT

Posted Date: April 13th, 2021

DOI: https://doi.org/10.21203/rs.3.rs-401912/v1

License: (c) (1) This work is licensed under a Creative Commons Attribution 4.0 International License.

Read Full License 


\title{
A DFT study of the impact of doping on the electronic and optical properties of indium nitride nanocage \\ Amarjyoti Das and Rajesh Kumar Yadav* \\ North Eastern Regional Institute of Science and Technology, Nirjuli 791109, Arunachal Pradesh, India \\ *Corresponding Author: rrpryadav@gmail.com
}

\begin{abstract}
:
Density functional theory (DFT) calculations are used to investigate the structural, electronic, and optical properties of the significant fullerene-like cage of $\operatorname{In}_{12} \mathrm{~N}_{12}$ nanoclusters with $\mathrm{Zn}$ (group II) and $\mathrm{Si}$ (group IV) dopants. In terms of formation energies and binding energies, the structural stability of the nanocages were studied. It has been seen that stability of the structure is slightly increases with the inclusion of doping. The study found that both the dopants significantly reduce the energy gap of the $\mathrm{In}_{12} \mathrm{~N}_{12}$ nanocluster. The electronic properties of the $\operatorname{In}_{12} \mathrm{~N}_{12}$ nanocluster seems to be sensitive to dopants, and it could be altered by a specific impurity. Moreover, electronic properties such as density of states (DOS) analysis, dipole moment, HOMO energies, LUMO energies, energy gaps, chemical potential, electron affinity, ionization potential, hardness, and electrophilicity index are also discussed. The optical absorption spectra of pure and doped nanocages were computed using TDDFT formalism. The maximum wavelength of the pure $\operatorname{In}_{12} \mathrm{~N}_{12}$ nanocage is moved towards higher wavelength region within the infrared region after doping with $\mathrm{Zn}$ and $\mathrm{Si}$, indicating a redshift.
\end{abstract}

Keywords: Nanocage, electronic properties, optical properties, DFT.

\section{Introduction}

A new generation of supramolecular chemistry has been introduced by discovery of $\mathrm{C}_{60}$ buckminsterfullerene [1] and nanotubes of carbon (CNT) [2]. Owing to their unique physical and chemical properties, fullerene-based materials have sparked a lot of interest. Fullerenes have shown promising applications in many of very important technological processes particularly in comparison to other carbon structures. Such as in the design of electronic devices, catalytic materials, superfibers, etc. [3-5]. It was observed that, after the discovery of fullerene, research is being carried out to obtain new classes of nearly or spherically stable materials, here called nanocages or nanoclusters.

Fullerene-like III-V and II-VI compound nanoclusters have drawn more attention due to their special semiconductor characteristics make them ideal for applications such as solar photocatalysts, optical sensitizers, photovoltaic cells, quantum devices, sensors, hydrogen storage and nanobiomedicine [6-10]. The synthesis of fullerenes followed by Li et al.[11], the properties of fullerene-like cages built up of non-carbon atoms have been studied in various works due to their superior physical and chemical properties [12,13]. However, because of their large band gaps, group III-V fullerene-like cages and tubular structures have been the focus of intensive research. Nanocages have been an important structure among these materials for several studies since their characteristics, such as their wide bandgap, unique chemical and physical attributes and low dependence on electrons [14-16]. In environmental structures, Baei [17] have demonstrated that the $\mathrm{B}_{12} \mathrm{~N}_{12}$ nanocage has the ability to be a good absorbent for toxic pyridine. Also, Beheshtian et al. [18] investigated $\mathrm{Al}_{12} \mathrm{~N}_{12}$ nanocage which could be potential candidate for Nitric oxide (NO) detection.

The progress of electronics focused on nanostructure and organic solar cells depends on our ability to tune the molecule's physical properties. Many methods have been developed to manufacture high-performance nanostructured devices to enhance their semiconducting properties by tuning their 
energy gaps. Recently, some researchers have used ab initio methods to study the different dopant interactions with the nanocluster, which offers valuable knowledge about the dopant behaviour [1923]. We've previously investigated that how doping influences the electronic, optical, and vibrational properties of nanosheets $[24,25]$. To the best of our knowledge, the physical properties of pure and doped $\operatorname{In}_{12} \mathrm{~N}_{12}$ nanocage has not yet been studied by ab- initio methods. Therefore, primary goal of this study is to eluisidate the electronic and optical properties of pure and $\mathrm{Si}$ and $\mathrm{Zn}$ doped, $\operatorname{In}_{12} \mathrm{~N}_{12}$ Nanocage using Density functional theory (DFT) method. The findings obtained are expected to pave a good approach for InN nanocluster in future nano-electronic and optical system applications.

\section{Computational details}

On the pure, Si and $\mathrm{Zn}$ doped $\operatorname{In}_{12} \mathrm{~N}_{12}$ nanoclusters geometry optimizations, DOS, and energy measurements were carried out using functional B3LYP with 6-31G(d,p) + LANL2DZ mixed basis set as implemented in the Gaussian-09 software. At the same time, frequency analysis was performed to detect the absence of imaginary frequency and to ensure that all stationary points on the potential energy surface corresponds to actual minima. B3LYP has also been shown to be a productive and effective functional for III-V semiconductor measurements, capable of correctly predicting both the electronic structure and ground state energies [26]. The LANL2DZ basis set was chosen because it provides an effective core potential (ECP) that takes relativistic effects on heavy atoms into account. In this case, core electrons represented by an ECP. According to the literature, the $6-31 \mathrm{G}(\mathrm{d}, \mathrm{p})+$ LANL2DZ mixed basis set significantly reduce the computational expense and accept both light and heavy dopants throughout the optimization process [27-30]. For molecular orbit visualisation, Gauss view 6.0 has been used. The density of states (DOS) was computed using the GaussSum program [31]. The optical absorption spectra were computed using TDDFT formalism following the calculations of the ground state.

\section{Calculations:}

The energy gap between LUMO and HOMO is an important factor in establishing molecular electric transport properties. We can easily determine various parameters such as Fermi energy $\left(E_{F}\right)$, hardness $(\eta)$, Electrophilicity $(\omega)$ by analysing HOMO and LUMO energy values [32]. By applying koopman's theorem, global reactivity parameters can be calculated by these following equations [33].

Ionisation potential $(\mathrm{IP})=-\mathrm{E}_{\mathrm{HOMO}}$

Electron affinity $(\mathrm{EA})=-\mathrm{E}_{\mathrm{LUMO}}$

Chemical potential $(\mu)=\frac{1}{2}\left(\mathrm{E}_{\mathrm{HOMO}}+\mathrm{E}_{\mathrm{LUMO}}\right)$

Hardness $(\eta)=\frac{1}{2}($ IP- EA)

Electrophilicity $(\omega)=\frac{\mu^{2}}{2 \eta}$

In terms of formation energy and binding energy per atom the structural stability of pure and doped InN nanocluster can be discussed as shown in equation (6) and (7)

$\mathrm{E}_{\text {form }}=\mathrm{xE}(\mathrm{In})+\mathrm{yE}(\mathrm{N})+\mathrm{E}($ dopant $)-\mathrm{E}(\mathrm{InN}$ nanocage/ doped InN nanocage $)$

$\mathrm{E}_{\mathrm{b}}=\frac{1}{\mathrm{n}} \mathrm{E}_{\text {form }}$

Here $\mathrm{x}, \mathrm{y}$ and $\mathrm{n}$ are number of In atom, $\mathrm{N}$ atom and the total number of atoms, respectively. 


\section{Results and discussions:}

\section{Electronic properties:}

A truncated octahedron consisting eight hexagons and six squares constitutes Indium nitride nanocage. $\operatorname{In}_{12} \mathrm{~N}_{12}$, a quantum cluster of 24 atoms, was used to represent the $\mathrm{InN}$ nanocage. To investigate the impacts of doping, an Indium atom is replaced by a $\mathrm{Zn}$ atom and a $\mathrm{Si}$ atom to form the nanocages $\operatorname{In}_{11} Z_{n N_{12}}$ and $\operatorname{In}_{11} \operatorname{SiN}_{12}$, respectively. A geometrical optimization for both the pure $\operatorname{In}_{12} \mathrm{~N}_{12}$ and the doped clusters, namely $\operatorname{In}_{11} \mathrm{ZnN}_{12}$ and $\operatorname{In}_{11} \mathrm{SiN}_{12}$ have been performed, which is depicted in the figure 1. As can be seen in fig. 1 (a) for pure $\operatorname{In}_{12} \mathrm{~N}_{12}$, the In and $\mathrm{N}$ sites are similar. Each In or $\mathrm{N}$ atom comprises three bonds with the three adjacent atoms in the same quad ring and bond length of In-N are $2.005 \AA, 2.091 \AA$ and $2.091 \AA$. When the bond lengths of pure and doped InN nanocages are compared, it is obvious that the $\mathrm{Zn}-\mathrm{N}$ and $\mathrm{Si}-\mathrm{N}$ bond lengths are shorter than the In-N bond lengths as shown in figure 1.

From the formation energy and binding energy per atom calculation which is calculated from equation (4) and (5) we can predict the stability of the structures. It has been seen that stability of the structure is slightly increases with the inclusion of doping. The formation energy of Pure, $\mathrm{Zn}$ and Si doped Indium nitride nanocage is $67.88 \mathrm{eV}, 70.44 \mathrm{eV}$ and $72.05 \mathrm{eV}$ respectively. The formation energy, binding energy per atom, dipole moment and point group of the optimized structures are shown in table 1 . The value of the dipole moment can be used to evaluate the charge distribution in the nanocage. The dipole moment of pure $\operatorname{In}_{12} \mathrm{~N}_{12}$ nanocage is minimal, it can be concluded that charges are distributed uniformly in the Pure $\mathrm{InN}$ nanocage. The dipole moment values of Pure, $\mathrm{Zn}$ and Si doped InN nanocage are 0.00, 2.07 and 1.71 Debye, respectively.

Frontier molecular orbital assists a major contribution in revealing optimized pure and doped InN nanocage electronic properties. In quantum mechanics, the highest occupied molecular orbital (HOMO) and lowest unoccupied molecular orbital (LUMO) energies are crucial parts. The concept of reactivity, as well as fundamental and physical properties of the atom, can be expressed by HOMOLUMO. HOMO tends to deliver electron sites as an electron donor, while LUMO comprises of free electron acceptance locations. The HOMO-LUMO energy gap is attributed to electrical conductivity and is used to determine the kinetic stability of a structure. The expression (8) represents the relationship between electrical conductivity $(\sigma)$ and energy gap $\left(\mathrm{E}_{\text {gap }}\right)$ at a given temperature $(\mathrm{T})$ [34].

$$
\sigma \propto \exp \left(-\frac{E_{\text {gap }}}{2 \mathrm{kT}}\right)
$$

Here, k denotes Boltzmann's constant.

It has been found that the energy gap of the nanocage contracts as a result of doping, implying that the insertion of impurity increases the electrical conductivity of the InN nanocage. The reduction of energy gap as follows; Pure $\operatorname{In}_{12} \mathrm{~N}_{12}>\operatorname{In}_{11} \mathrm{ZnN}_{12}>\operatorname{In}_{11} \operatorname{SiN}_{12}$ nanocage. Our calculated energy gap is smaller than previously calculated energy gap by Zhao et al.[35]. On the other hand, hardness and chemical potential are two significant factors for investigating the nanocage's reactivity and behavior. Small hardness and chemical potential values indicate a structure with high reactivity and activity, making it a good choice for a sensing device. A high IP and EA value indicates a pleasant environment for chemical sensors. Electrophilicity is a global indices parameter that determines the tendency to accept electrons from atoms or molecules. Table 2 shows that electrophilicity is lowest (highest) while hardness and chemical potential are highest (lowest) [36-38].

HOMO-LUMO's pictorial interpretation enables us to distinguish certain regions where electron density is localized. In figure 2-4, visualization of the HOMO-LUMO and Density of state 
(DOS) of both pure and dopant structure are shown. The energy gap narrows as impurities are substituted, as seen in the figures. The sensitivity of the InN nanocage to a particular dopant can be due to the change in the HOMO-LUMO gap generated by impurity substitution, ensuring that we can change the electronic properties by using a certain impurity. The density of state spectrum reveals where charge is located in the valence and conduction bands. This is directly found in the DOS spectrum, which shows that with the inclusion of impurity, the charge location is more in the valence band, as seen by the increased number of peaks in the valence band. Especially, the inclusion of dopant results in the existence of alpha and beta orbitals. As electrons spin up and down, however, those orbitals are appearing.

\section{Optical properties:}

The absorption spectra of pure and $\mathrm{Zn}, \mathrm{Si}$ doped $\mathrm{InN}$ nanocages were investigated using the time dependent density functional theory at the B3LYP/6-31G(d,p) + LANL2DZ level. Zinc and Silicon substituted nanocages have been shown to have higher absorption wavelength values than pure $\mathrm{InN}$ nanocage. The wavelength of pure $\operatorname{In}_{12} \mathrm{~N}_{12}$ is $913.75 \mathrm{~nm}$, while the wavelengths of $\operatorname{In}_{11} \mathrm{ZnN}_{12}$ and $\mathrm{In}_{11} \mathrm{SiN}_{12}$ nanocages are $2686.28 \mathrm{~nm}$ and $1199.33 \mathrm{~nm}$, respectively. In the following order, the overall absorption wavelength increases: pure $\operatorname{In}_{12} \mathrm{~N}_{12}<\operatorname{In}_{11} \operatorname{SiN}_{12}<\operatorname{In}_{11} \mathrm{ZnN}_{12}$.

Based on the measured wavelength we may deduce that pure $\mathrm{InN}$ nanocage is in the infrared region, which is due to the electronic transition HOMO $\rightarrow$ LUMO. The far infrared region was followed by the nanocage with $\mathrm{Zn}$ substitution, which was associated with the electronic transition HOMO $\rightarrow$ LUMO, which contributed significantly. On the other hand, Silicon doped nanocage is in the infrared region and is due to the electronic transition HOMO-1 $\rightarrow$ LUMO.

The insertion of silicon to the InN nanocage reduces the oscillator strength. In the case of $\mathrm{Zn}$ substituted Nanocage, however, the opposite is true. The absorption spectra of pure $\operatorname{In}_{12} \mathrm{~N}_{12}$, $\mathrm{In}_{11} \mathrm{ZnN}_{12}$, and $\mathrm{In}_{11} \mathrm{SiN}_{12}$ nanocages have oscillator strengths of $0.0004,0.0027$, and 0.0001 , respectively. Figure 5 displays the absorption spectra of pure and doped $\mathrm{InN}$ nanocages. Table 3 shows the values for excitation energies, oscillator strength, maximum absorption wavelength and electronic transition.

\section{Conclusion:}

In the present study, DFT calculation were done to examine how electronic and optical properties can be tailored with the implementation of doping. The bond length, which signify various interactions between the dopant atom and the host atoms, appears to be dependent on the type of dopant atoms, according to the results. This is due to the fact that each dopant has a distinct atomic radius. Bond lengths are found to decreases as the atomic number of the dopants decreases in the periodic table. The stability of the InN nanocage can be improved by doping it with $\mathrm{Zn}$ and $\mathrm{Si}$ dopants. It's worth noting that, if the forming energy is minimum, the smoother the substitution is. Different band gaps are observed depending on the type of doped atom. This is due to the effect of hybridization and the transfer of electrons between $\mathrm{N}$ and doped atoms that occurs when the nanocage is doped with $\mathrm{Zn}$ and $\mathrm{Si}$. As a result, the nanocage electrical conductivity can be tuned more easily with doping. The lowest hardness value of $\mathrm{Zn}$ doped nancage indicates that it has a higher tendency to accept or donate electrons. The maximum wavelength of the pure $\operatorname{In}_{12} \mathrm{~N}_{12}$ nanocage is moved towards higher wavelength within the infrared region after doping with $\mathrm{Zn}$ and $\mathrm{Si}$, indicating a redshift. We hope that the findings of this study pave the way for more experimental and theoretical research on InN nanocages in the future. 


\section{Author contribution}

The problem was conceptualised by Amarjyoti Das. Amarjyoti Das conducted the investigation and wrote the original report and R.K. Yadav supervised the work undertaken. Both are working on anticipated outcome analysis.

\section{Funding}

No funding was received for conducting this study.

Availability of data and material

Not applicable.

\section{Consent to Publish}

Not applicable.

\section{Consent to Participate}

Not applicable.

\section{Acknowledgements}

The authors are glad to DST, New Delhi, India, for providing the financial support as DSTInspire fellowship.

\section{Conflict of interest}

There are no conflicts of interest declared by the authors.

\section{References:}

1. Kroto, H., Heath, J., O'Brien, S. et al. $\mathrm{C}_{60}$ : Buckminsterfullerene. Nature 318, 162-163 (1985).

2. S. Iijima, Helical microtubules of graphitic carbon, Nature 354 56-58(1991).

3. D. Golberg, Y. Bando, O. Stéphan, K. Kurashima, Appl. Phys. Lett. 73 2441(1998).

4. O. Stéphan, Y. Bando, A. Loiseau, F. Willaime, N. Shramchenko, T. Tamiya, T. Sato, Appl. Phys. A 67 107(1998).

5. T. Oku, A. Nishiwaki, I. Narita, Sci. Tech, Adv. Mater 5 635(2004).

6. Chakrabarti, R., Dutta, J., Bandyopadhyay, S., Bhattacharyya, D., Chaudhuri, S., \& Pal, A. K., Solar energy materials and solar cells, 61(2), 113-126(2000).

7. Beheshtian, J., Kamfiroozi, M., Bagheri, Z., \& Ahmadi, A, Computational materials science, 54, 115-118(2012).

8. Sebastian, P. J., \& Ocampo, M, Solar energy materials and solar cells, 44(1), 1-10(1996).

9. Reber, A. C., Khanna, S. N., Hunjan, J. S., \& Beltran, M. R, The European Physical Journal D, 43(1), 221-224(2007).

10. Wang, B., Nagase, S., Zhao, J., \& Wang, G, The Journal of Physical Chemistry C, 111(13), 4956-4963(2007).

11. Compagnini, G., Sinatra, M. G., Messina, G. C., Patanè, G., Scalese, S., \& Puglisi, O, Applied surface science, 258(15), 5672-5676(2012).

12. Li, F., Yager, K. G., Dawson, N. M., Jiang, Y. B., Malloy, K. J., \& Qin, Y.,Chemistry of Materials, 26(12), 3747-3756(2014).

13. Oku, T., Nishiwaki, A., \& Narita, I, Solid state communications, 130(3-4), 171-173(2004).

14. Zhang, F., Wu, Q., Wang, X., Liu, N., Yang, J., Hu, Y., \& Zhu, J, The Journal of Physical Chemistry C, 113(10), 4053-4058(2009).

15. Wu, Q., Zhang, F., Wang, X., Liu, C., Hu, Z., \& Lu, Y, The Journal of Physical Chemistry C, 111(34), 12639-12642(2007).

16. Lei, W., Liu, D., Zhang, J., Zhu, P., Cui, Q., \& Zou, G, Crystal Growth and Design, 9(3), 1489-1493(2009).

17. Baei, M. T, Superlattices and Microstructures, 58, 31-37(2013). 
18. Beheshtian, J., Peyghan, A. A., \& Bagheri, Z, Computational materials science, 62, 7174(2012).

19. Tahmasebi, E., Shakerzadeh, E., \& Biglari, Z, Applied Surface Science, 363, 197-208(2016).

20. Hadipour, N. L., Ahmadi Peyghan, A., \& Soleymanabadi, H, The Journal of Physical Chemistry C, 119(11), 6398-6404(2015).

21. Dheivamalar, S., \& Banu, K. B, Heliyon, 5(12), e02903(2019).

22. Omidvar, A, Vacuum, 147, 126-133(2018).

23. Zhihong, Y., Ye, Y., Pejhan, A., Nasr, A. H., Nourbakhsh, N., \& Tayebee, R, Applied Organometallic Chemistry, 34(4), e5534(2020).

24. Das,A.,Yadav,R.K., Struct chem,32,379-386 (2021).

25. Das,A.,Yadav,R.K., Struct chem,(2021). https://doi.org/10.1007/s11224-020-01695-6.

26. Tomić, S., Montanari, B., \& Harrison, N. M, Physica E: Low-dimensional Systems and Nanostructures, 40(6), 2125-2127(2008).

27. Yang, Y., Weaver, M. N., \& Merz Jr, K. M, The Journal of Physical Chemistry A, 113(36), 9843-9851(2009).

28. Rad, A. S., \& Abedini, E, Applied Surface Science, 360, 1041-1046(2016).

29. Lyngvi, E., \& Schoenebeck, F, Tetrahedron, 69(27-28), 5715-5718(2013).

30. Thakur, S., Borah, S. M., Singh, A., \& Adhikary, N. C, Applied Physics A, 126(2), 111(2020).

31. O'boyle, N. M., Tenderholt, A. L., \&Langner, K. M, Journal of computational chemistry, 29, 839-845(2008).

32. Suh, Y. J., Chae, J. W., Jang, H. D., \& Cho, K , Chemical Engineering Journal, 273, 401405(2015).

33. Koopmans, T., Physica, 1, 104-113(1934).

34. Li, S. S. Semiconductor physical electronics. Springer Science \& Business Media (2012).

35. Zhao, R. N., Chen, R., \& Han, J. G. Microporous and Mesoporous Materials, 111041 (2021).

36. Chamorro, E.; Chattaraj, P. K.; Fuentealba, P, J. Phys. Chem. A 107, 7068-7072(2003).

37. Chattaraj, P. K.; Gutierrez- Oliva, S.; Jaque, P.; Toro-Labbe, A. Mol. Phys. 101, 28412853(2003).

38. Parthasarathi, R.; Elango, M.; Subramanian, V.; Chattaraj, P. K, Theor. Chem. Acc. 113, $257-$ 266, (2005). 


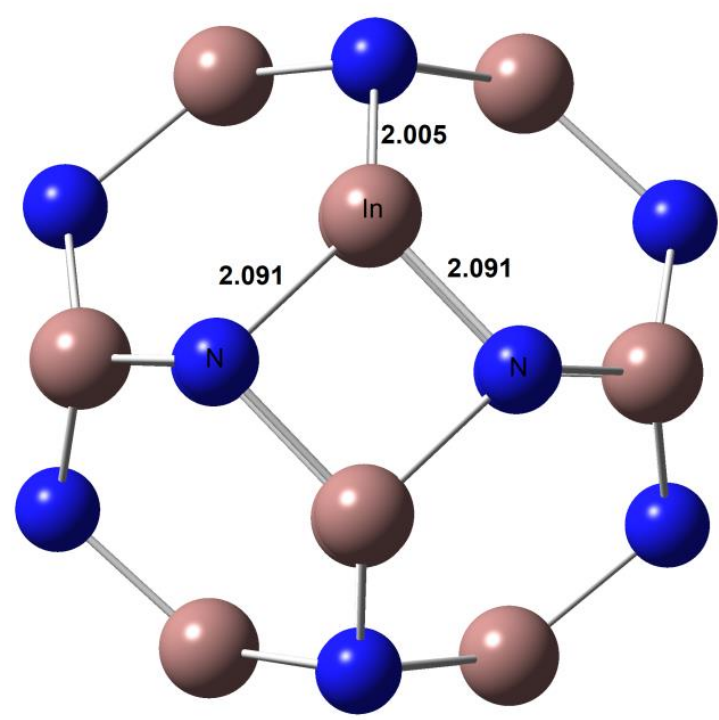

A

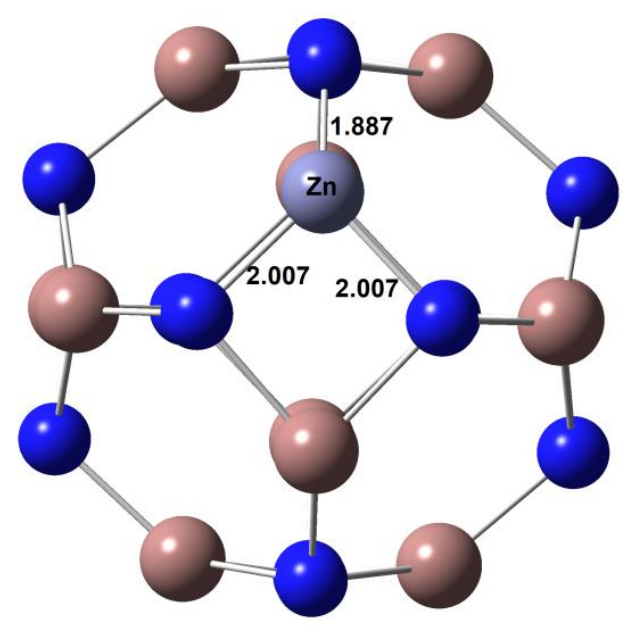

B

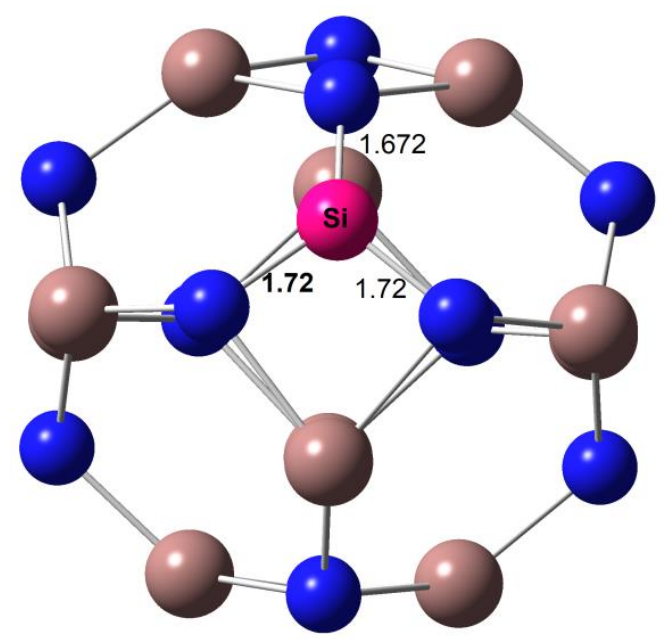

C

Figure 1: Optimized structure of A) Pure $\operatorname{In}_{12} \mathrm{~N}_{12}$ Nanocage B) $\operatorname{In}_{11} \mathrm{ZnN}_{12}$ Nanocage C) $\operatorname{In}_{11} \mathrm{SiN}_{12}$ Nanocage .All the bond lengths are in $\AA$. 

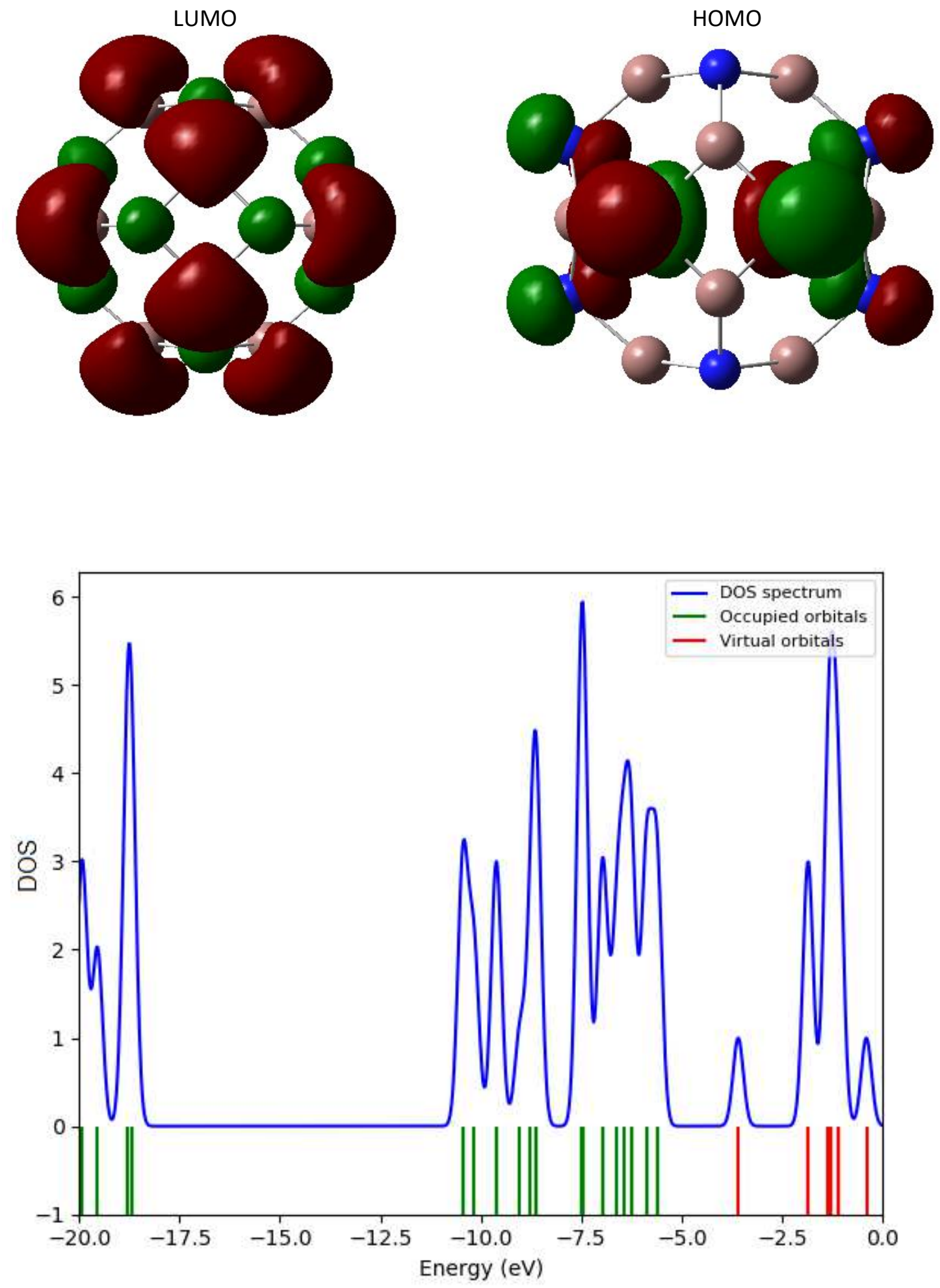

Figure 2: Visualization of HOMO-LUMO and Density of states (DOS) of Pure $\operatorname{In}_{12} \mathrm{~N}_{12}$ Nanocage. 



Figure 3: Visualization of HOMO-LUMO and density of states (DOS) of $\operatorname{In}_{11} \mathrm{ZnN}_{12}$ Nanocage. 
LUMO



HOMO

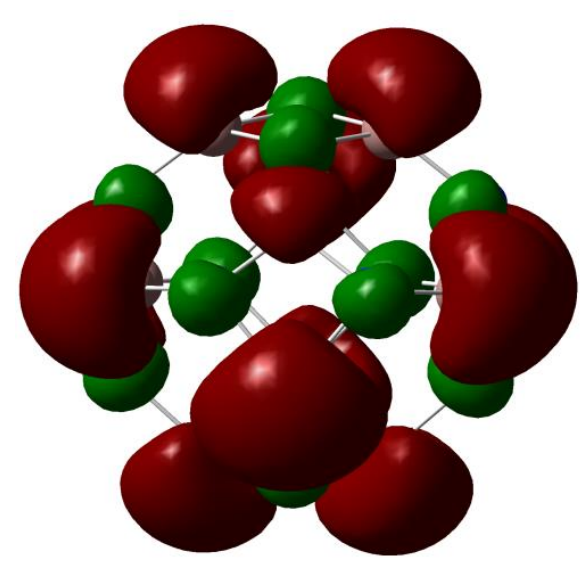

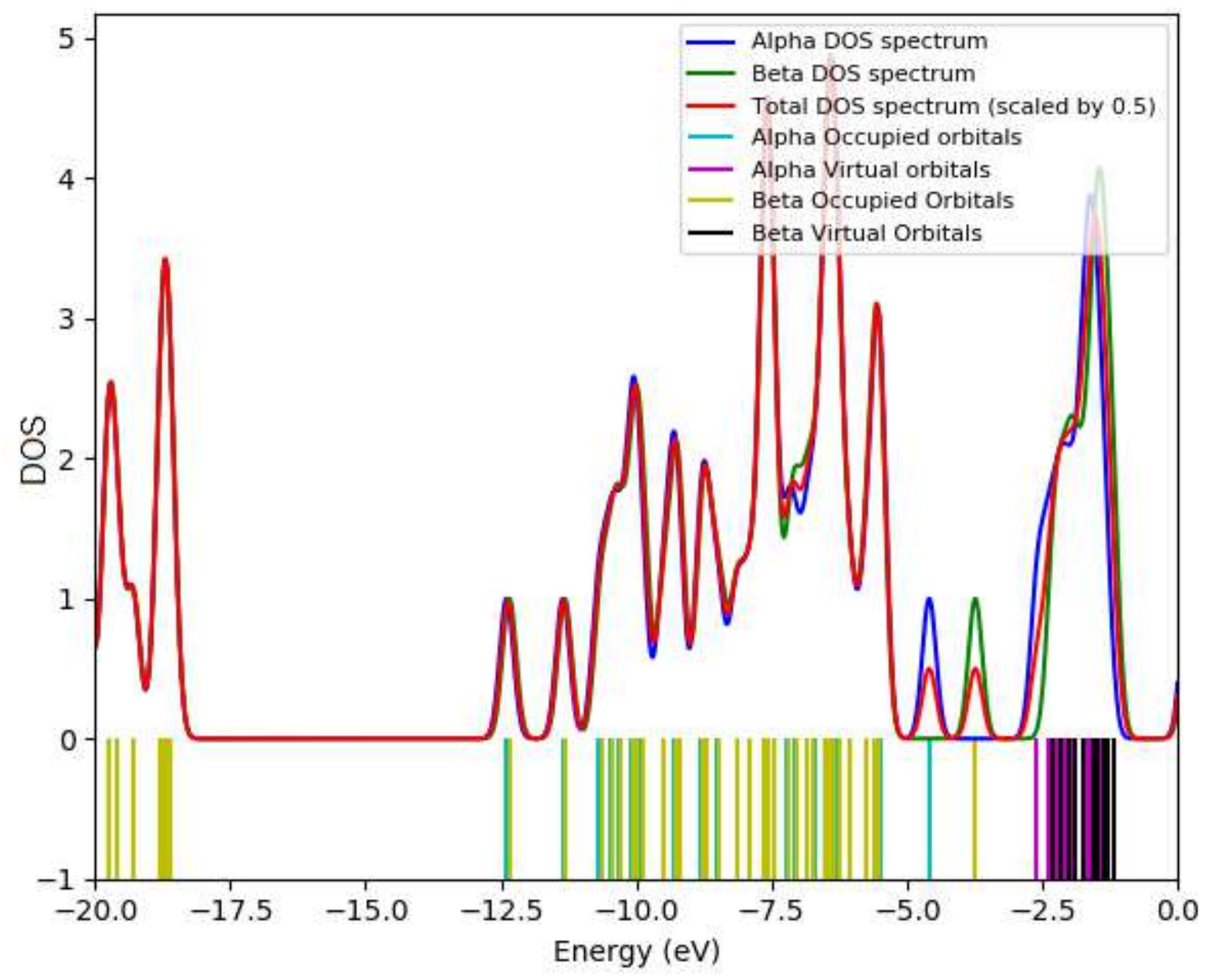

Figure 4: Density of states (DOS) and visualization of HOMO-LUMO of $\operatorname{In}_{11} \mathrm{SiN}_{12}$ Nanocage. 




Figure 5: Absorption spectra of Pure and doped Indium nitride Nanocage. 
Table 1: Calculated formation energy, binding energy per atom, dipole moment and point group of pure and doped InN nanocages.

\begin{tabular}{|l|c|c|c|c|}
\hline Nanocage & $\begin{array}{c}\text { Formation } \\
\text { energy } \\
(\mathrm{eV})\end{array}$ & $\begin{array}{c}\text { Binding } \\
\text { energy per } \\
\text { atom } \\
(\mathrm{eV})\end{array}$ & $\begin{array}{c}\text { Dipole } \\
\text { moment } \\
\text { (Debye) }\end{array}$ & Point group \\
\hline Pure $\mathrm{In}_{12} \mathrm{~N}_{12}$ & 67.88 & 2.83 & 0.00 & $\mathrm{~T}_{\mathrm{h}}$ \\
\hline $\mathrm{In}_{11} \mathrm{ZnN}_{12}$ & 70.44 & 2.93 & 2.07 & $\mathrm{C}_{\mathrm{s}}$ \\
\hline $\mathrm{In}_{11} \mathrm{SiN}_{12}$ & 72.08 & 3.00 & 1.71 & $\mathrm{C}_{\mathrm{s}}$ \\
\hline
\end{tabular}

Table 2: Computed ionization potential (IP), electron affinity (EA), chemical potential $(\mu)$, hardness $(\eta)$, electrophilicity index $(\omega)$ and energy gap $\left(E_{g a p}\right)$ of pure and doped $\mathrm{InN}$ nanocages.

\begin{tabular}{|c|c|c|c|c|c|c|}
\hline Nanocage & $\begin{array}{c}\text { Ionization } \\
\text { potential } \\
(\mathrm{IP}) \\
(\mathrm{eV})\end{array}$ & $\begin{array}{c}\text { Electron } \\
\text { affinity } \\
(\mathrm{EA}) \\
(\mathrm{eV})\end{array}$ & $\begin{array}{c}\text { Chemical } \\
\text { potential } \\
(\mu) \\
(\mathrm{eV})\end{array}$ & $\begin{array}{c}\text { Hardness } \\
(\eta) \\
(\mathrm{eV})\end{array}$ & $\begin{array}{c}\text { Electrophilicity } \\
\text { index }(\omega) \\
(\mathrm{eV})\end{array}$ & $\begin{array}{c}\text { Energy gap } \\
(\mathrm{E}) \\
(\mathrm{eV})\end{array}$ \\
\hline $\begin{array}{c}\text { Pristine } \\
\mathrm{In}_{12} \mathrm{~N}_{12}\end{array}$ & 5.62 & 3.59 & -4.61 & 1.02 & 10.42 & 2.03 \\
\hline $\mathrm{In}_{11} \mathrm{ZnN}_{12}$ & 5.21 & 3.96 & -4.59 & 0.63 & 16.72 & 1.25 \\
\hline $\mathrm{In}_{11} \mathrm{SiN}_{12}$ & 4.49 & 3.64 & -4.07 & 0.43 & 19.26 & 0.85 \\
\hline
\end{tabular}

Table 3: Maximum excitation energy $\left(\mathrm{E}_{\max }\right)$, maximum absorption wavelengths $\left(\lambda_{\max }\right)$, oscillator strength (f) and electronic transitions of pure and doped $\mathrm{InN}$ nanocages.

\begin{tabular}{|l|c|l|l|l|}
\hline Nanocage & $\begin{array}{c}\text { Maximum Excitation } \\
\text { energy E } \\
(\mathrm{eV})\end{array}$ & $\begin{array}{l}\lambda_{\max } \\
(\mathrm{nm})\end{array}$ & $\begin{array}{l}\text { Oscillator } \\
\text { strength } \\
(\mathrm{f})\end{array}$ & Electronic transition \\
\hline Pure $\mathrm{In}_{12} \mathrm{~N}_{12}$ & 1.36 & 913.75 & 0.0004 & HOMO $\rightarrow$ LUMO (99\%) \\
\hline $\mathrm{In}_{11} \mathrm{ZnN}_{12}$ & 0.46 & 2686.28 & 0.0027 & HOMO $\rightarrow$ LUMO (97\%) \\
\hline $\mathrm{In}_{11} \mathrm{SiN}_{12}$ & 1.03 & 1199.33 & 0.0001 & HOMO $-1 \rightarrow$ LUMO $(98 \%)$ \\
\hline
\end{tabular}


Figures

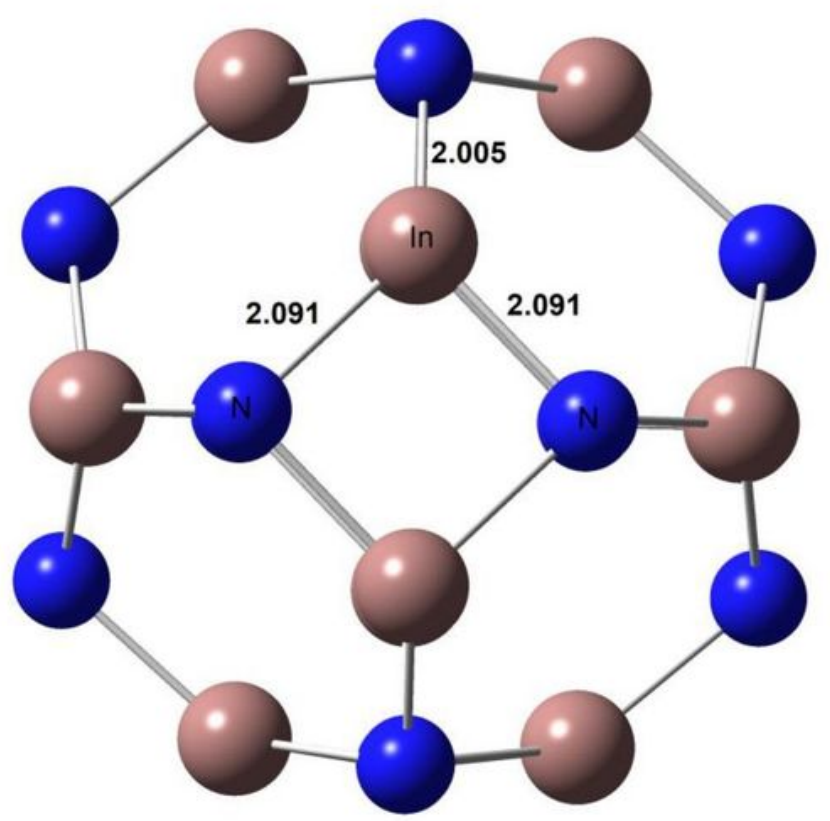

A

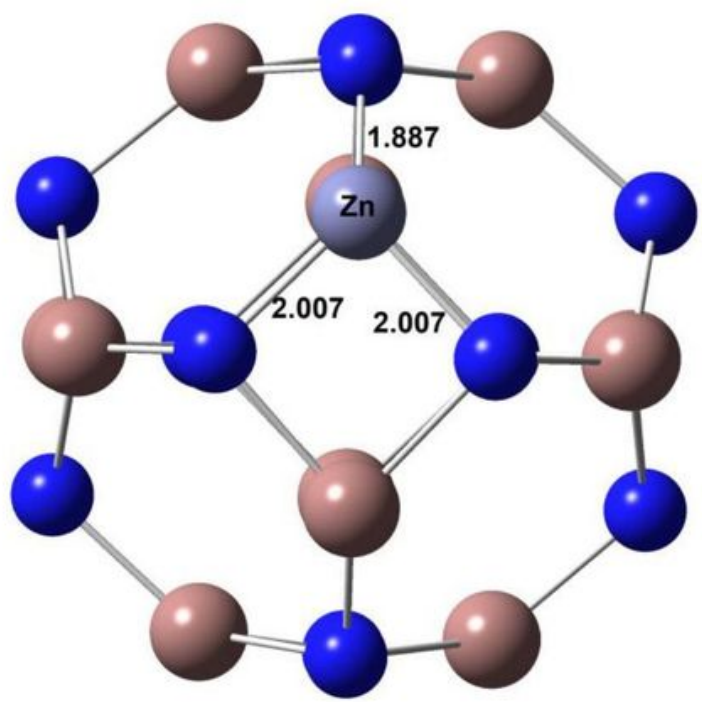

B

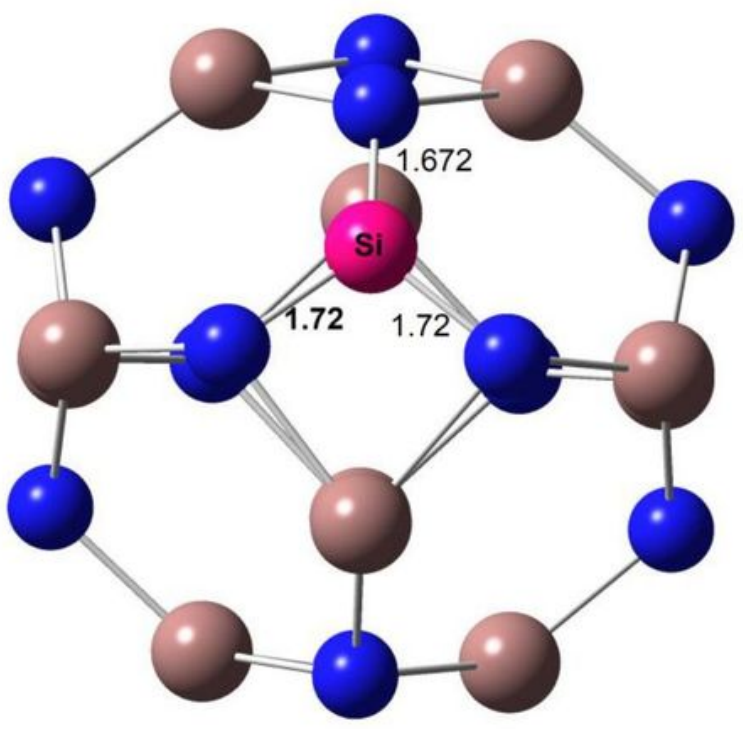

C

Figure 1

Optimized structure of A) Pure In12N12 Nanocage B) In11ZnN12 Nanocage C) In11SiN12 Nanocage .All the bond lengths are in $\AA$. 

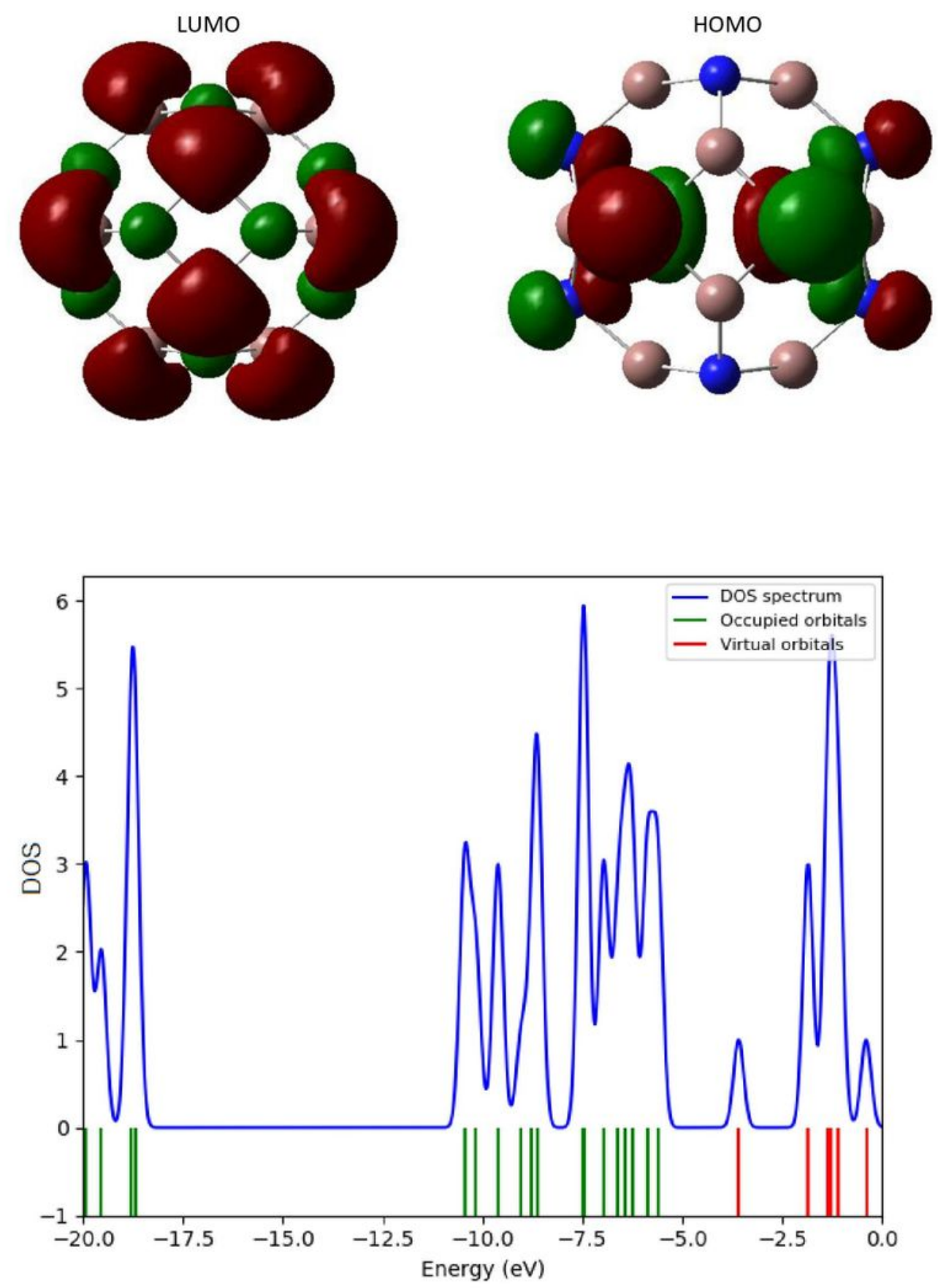

Figure 2

Visualization of HOMO-LUMO and Density of states (DOS) of Pure In12N12 Nanocage. 

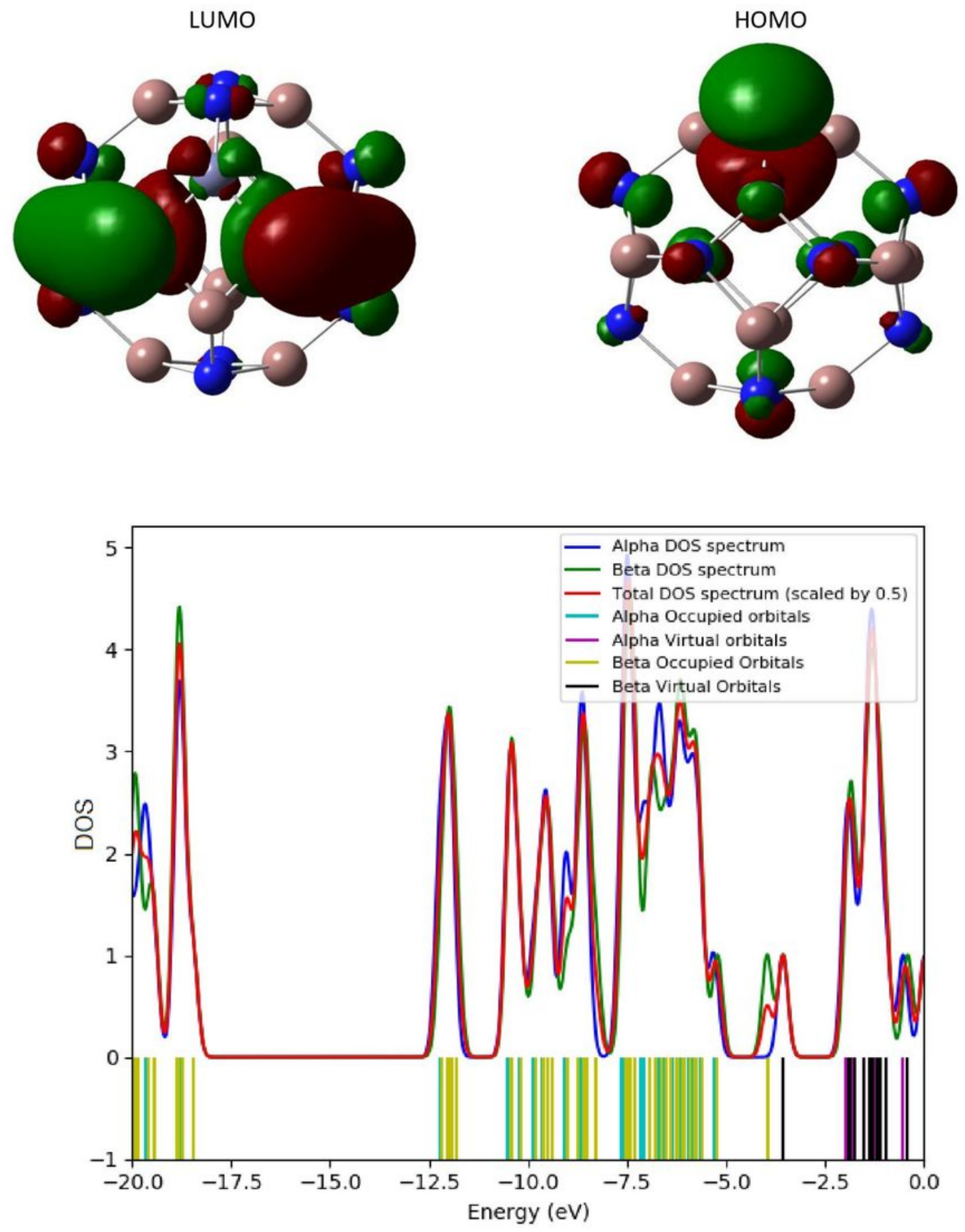

Figure 3

Visualization of HOMO-LUMO and density of states (DOS) of In11ZnN12 Nanocage. 

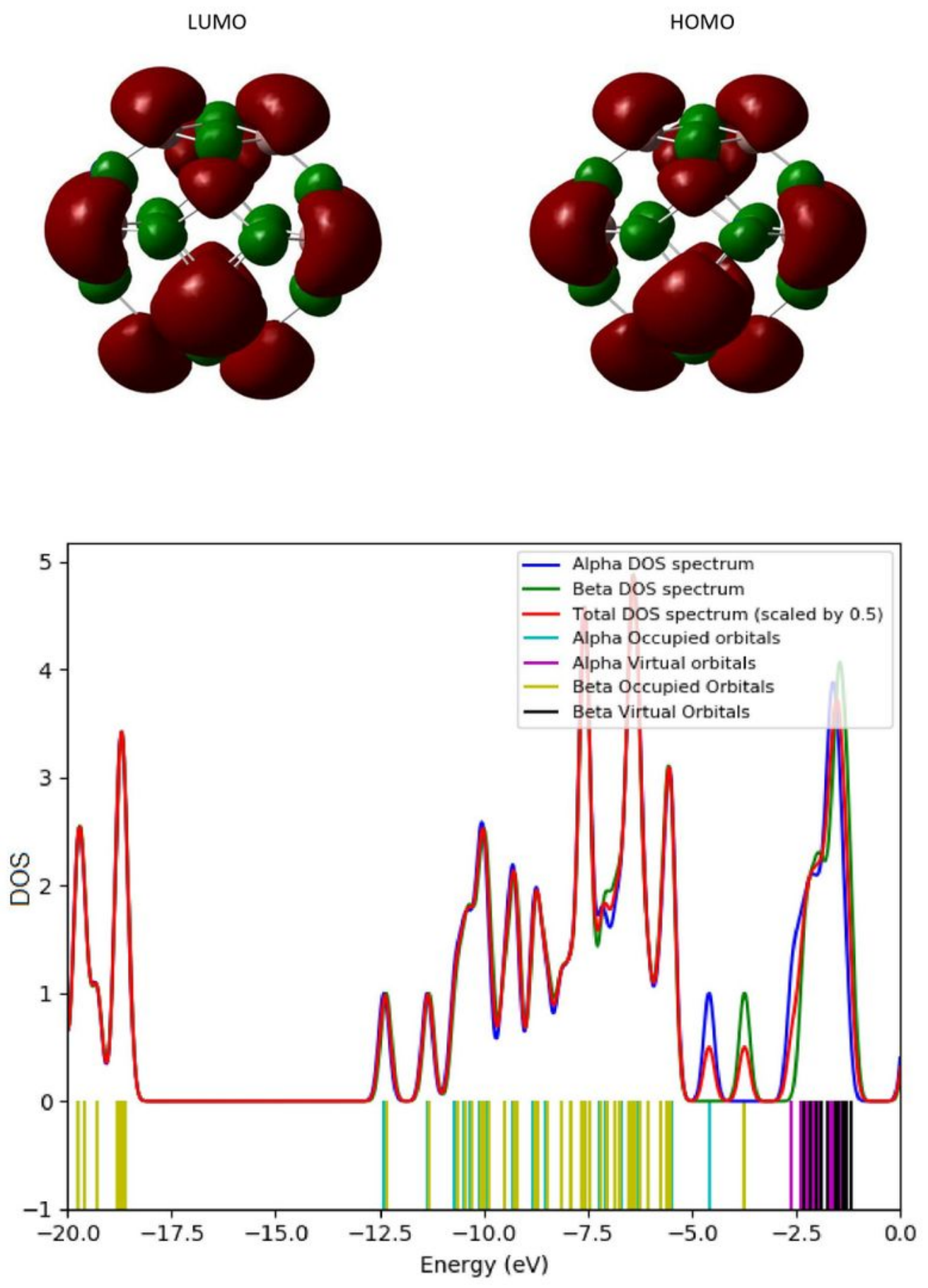

Figure 4

Density of states (DOS) and visualization of HOMO-LUMO of In11SiN12 Nanocage. 




Figure 5

Absorption spectra of Pure and doped Indium nitride Nanocage. 